\title{
Ang Pilosopiya ni Emerita S. Quito
}

\section{Leslie Anne L. Liwanag}

\begin{abstract}
This paper is a study on how a female professor of philosophy became a leading figure in the development of Filipino philosophy. Emerita Quito, of De La Salle University, is probably the greatest philosopher in contemporary Philippines. This paper contains the following substantive parts: 1) her theoretical and praxiological foundation; 2) her reflective thoughts on Filipino philosophy; 3) her method of philosophizing; 4) her praxiology; and 5) her views about the Philippine society. This paper concludes with a discussion on how her thoughts impacted Filipino philosophy.
\end{abstract}

Keywords: Quito, manifestations of Filipino philosophy, theory and praxiology, discourse

\section{Introduksyon}

Mithiin ng papel na itong maibahagi ang mahahalagang aspekto at puntos ng kaisipan ng pilosopong Pilipina at propesor na si Emerita S. Quito (1929), na hindi maitatatuwang nagkaroon ng malaking ambag sa pag-aaral ng kairalan ng Pilosopiyang Pilipino. Gayunman, hindi naging lihim sa kanya ang kakulangan sa paglaganap ng kahalagahan at kakapusan sa pokus ng larangang ito sa bansa. May layunin ang pag-aaral na itong matukoy ang mga puntos ng pamimilosopiya at diskurso ni Quito upang mapalakas at mapalinang ang araling kultural at araling Pilipino, sa pamamagitan ng tekstwal na proyektong ito ukol sa pilosopiya ng isang lokal na pantas.

\section{Intelektwal na Talambuhay ni Quito}

Ipinanganak si Quito noong ika-11 ng Setyembre, 1929 sa San Fernando, Pampanga. Bilang bunso sa magkakapatid, hindi ipinagkait sa 
kanya ang hilig sa mga libro gaya ng kanyang mga magulang. ${ }^{1}$ Hinangad ni Quito ang kursong abogasya, kaya agarang pumasok sa kursong pilosopiya sa Unibersidad ng Santo Tomas (UST) at natapos ang digri sa batsilyer noong 1949. Nahulog ang loob sa nasabing disiplina, ipinagpatuloy niya ang gradwadong programa sa naturang unibersidad at natamo ang digri sa masteral noong 1956.

Noong lumisan si Quito ng Pilipinas noong 1961, puspusan ang kanyang naging pag-aaral sa iba't ibang pilosopiya sa Europa at umahon mula sa pagkakalunod sa Tomismo ng UST. Sa Europa, natapos ni Quito ang digri sa doktorado sa Universite de Fribourg, Switzerland noong 1965 na may disertasyon na may titulong "La Notion de la Liberte Participee dans la Philosophie de Louis Lavelle." Bumalik siya sa Pilipinas at nagturo sa UST noong 1967. Naunsyami si Quito sa Eskolastisismo at Tomismo ng UST at kakapusan sa imprastraktura ng pananaliksik para sa mga fakulti at magaaral. Mula rito, sinubukan niyang magturo sa Pamantasang Ateneo de Manila at Kolehiyo ng Assumption hanggang sa imbitahan siya ni Br. Andrew Gonzalez na lumipat sa Pamantasang De La Salle (DLSU).

Ginanahang manaliksik sa DLSU si Quito sapagkat maraming insentibo sa pagsasagawa ng mga pag-aaral. Alinsunod dito ang pagiging fultaym fakulti pa sa nasabing institusyon noong 1971. Nagkaroon rin siya ng oportunidad na makakuha ng post-doctoral fellowships at grants sa Universitat Wien, Austria noong 1962, sa Universidad de Zaragoza, Spain noong 1964. Isinulong niya pa ang pagsasanay sa pilosopiyang oriental at Sanskrit sa Universite de Paris-Sorbonne, France noong 1974. Pinangunahan ni Quito ang pagbubukod sa orihinal na estilong Eskolastisismo at Tomismong pamimilosopiya sa DLSU. Nagretiro siya sa nasabing institusyon bilang full professor at professor emeritus noong 1993.

\section{Ang mga Obra ni Quito}

May dalawang listahang natagpuan ang mananaliksik na maituturing na pinakakomprehensibong mga tala ng mga nailathalang obra ni Quito: una, ang isa sa mga apendiks ng tesis na may pamagat na Ang Kaganapan ng Isang Dalubhasa sa Pilosopiya na nasa Foronda Collection ng Aklatan ng Pamantasang De La Salle, at pangalawa, ang pinakahuling curriculum vitae ni Quito na kasalukuyang nakatago sa Departamento ng Pilosopiya nang magretiro siya sa Pamantasang De La Salle. Gawa ng isa si Quito sa mga unang nagsulong na maging sentro sa pananaliksik ang Pamantasang De La Salle, tunay na napakarami ang kanyang naging

${ }^{1}$ Janet Jimenez, et. al., Ang Kaganapan ng Isang Dalubhasa sa Pilosopiya (Thesis, Manila: De La Salle University, 1990), 1.

(C) 2016 Leslie Anne L. Liwanag

http://www.kritike.org/journal/issue 18/liwanag june2016.pdf

ISSN 1908-7330

(cc) BY-NC-ND 


\section{PILOSOPIYA NI EMERITA QUITO}

publikasyon. Sa katunayan, taong 1990 noong gawaran siya ng Pamantasang ito ng isang festschrift ("festival of writings") na may titulong A Life of Philosophy: A Festschrift in Honor of Emerita S. Quito na naglalaman ng kanyang piling-piling mga publikasyon.

Kasama mismo si Quito sa lupong pumili at sumala sa mga monograph at artikulong isinama sa festschrift, kaya minarapat na gamitin ito bilang prinsipyo sa pagpapasyang maging bahagi ang mga artikulong kabilang sa kabuoang aklat:

\begin{tabular}{|c|c|}
\hline Taon & Mga Akda ni Quito sa Festschrift \\
\hline \multirow{9}{*}{$1965-1970$} & A New Concept of Philosophy \\
\hline & $\begin{array}{l}\text { La Notion de la Liberte Participee dans la Philosophie } \\
\text { de Louis Lavelle }\end{array}$ \\
\hline & Herbert Marcuse and Contemporary Society \\
\hline & The Philosophy of Henri Bergson \\
\hline & The Symposium of Plato \\
\hline & Existential Principles and Christian Morality \\
\hline & The Phenomenology of Edmund Husserl \\
\hline & The Theme of Absurdity in Albert Camus \\
\hline & Should Communism be Taught in our Universities \\
\hline \multirow{14}{*}{$1971-1980$} & Ang Pilosopiya sa Diwang Pilipino \\
\hline & Ang Kasaysayan ng Pilosopiya \\
\hline & Oriental Roots of Occidental Philosophy \\
\hline & Four Essays in the Philosophy of History \\
\hline & Lectures on Comparative Philosophy \\
\hline & Structuralism: A General Introduction \\
\hline & Reflections on the Death of God \\
\hline & Robert Ardrey: Scientist or Philosopher \\
\hline & The Historical Concept of Being and Truth \\
\hline & The Philosophy of the Renaissance: Nicolas of Cusa \\
\hline & Yoga and Christian Spirituality \\
\hline & $\begin{array}{l}\text { The Role of the University in Changing } \\
\text { Women's Consciousness }\end{array}$ \\
\hline & Ang Kayamanan ng Wikang Filipino \\
\hline & Process Philosophy: An Introduction \\
\hline \multirow{8}{*}{ 1981-1988 } & Homage to Jean-Paul Sartre \\
\hline & Three Women Philosophers \\
\hline & Ang Pilosopiya: Batayan ng Pambansang Kultura \\
\hline & An Existentialist Approach to Ecumenism \\
\hline & Teaching and Research of Philosphy in the Philippines \\
\hline & Values as a Factor in Social Action \\
\hline & Structuralism and the Filipino Volksgeist \\
\hline & Isang Teoriya ng Pagpapahalaga \\
\hline
\end{tabular}

(c) 2016 Leslie Anne L. Liwanag http://www.kritike.org/journal/issue 18/liwanag june2016.pdf ISSN 1908-7330 


\begin{tabular}{|l|l|}
\hline & A Filipino Volksgeist in Vernacular Literature \\
\cline { 2 - 2 } & Philosophy of Education for Filipinos \\
\hline
\end{tabular}

Table 1: Seleksyon ng mga Pangunahing Publikasyon ni Quito mula sa "A life of Philosophy: Selected Works of Emerita S. Quito (1965-1988)"

Bukod sa intelektwal na talambuhay ni Quito at pagbalik-tanaw sa kanyang mga obra, nakapokus ang papel sa anim na aspekto ng kanyang kaisipan: 1) ang kanyang teoretikal at praksiyolohikal na batis; 2) ang kanyang replektibong pananaw sa pilosopiya; 3) ang kanyang diskursibong katayuan sa pilosopiyang Pilipino; 4) ang kanyang metodo sa pamimilsopiya; 5) ang kanyang praksiyolohiya; at 6) ang kanyang pananaw sa lipunang Pilipino.

\section{Teoretikal at Praksiyolohikal na Batis Ni Quito}

Nagtapos si Quito sa UST na may reputasyon sa pagkakaroon ng pilosopiyang nakasentro sa Eskolastisismo at Tomismo bilang sistema ng kaisipan. Nakaposisyon ang Tomismo sa pangunguna ni Santo Tomas de Aquino (1227-1274) na isang teolohista, pilosopo, at hinirang na Doktor ng Simbahan. Malinaw na ipinapahayag ng pinakatanyag na paksa ng pilosopiya ng Tomismo ang pagpilit ni Santo Tomas na pagkasunduin ang pag-iisip ni Aristoteles at ang pag-iisip ng Kristiyano.. Matatagpuan ang kanyang teolohiya sa Summa Theologica, ang pinakamaimpluwensiyang dokumentong patuloy na ginagamit bilang sanggunian ng pilosopiya at teolohiya ng Simbahang Katoliko. Nakasaad dito ang maningning na pagkakabalangkas ng kanyang mga argumentong nauukol sa usapin ng kairalan ng Diyos, paglikha at tunguhin ng tao, si Kristo, at ang mga Sakramento. Tinangka ring panindigan ni Santo Tomas na ang Diyos ang Unang Sanhi. Walang anomang gawain ang maaaring mangyari kung walang kapahintulutan ng Diyos. Ngunit hindi nagmumula sa Diyos ang kasiraan sa anomang kilos o gawa ng tao. ${ }^{3}$

Sa puntong ito, masasabing mahalagang makita na naging matapat sa Tomismo si Quito bilang produkto ng institusyong ito-bagay na napatunayan sa kanyang tesis para sa masteral na digri na pinamagatang "The Will and its Relation to Divine Casuality and Knowledge" na isinumite sa Unibersidad ng Sto. Tomas (UST) noong 1956. Tinalakay niya sa tesis na ito ang sinauna pang problema ukol sa kalayaan ng pagpapasya (freedom of the will). Alinsunod dito ang pagbusisi ni Quito sa depinisyon ng kagustuhan

${ }^{2}$ Emerita Quito, "Kasaysayan ng Pilosopiya," in A Life of Philosophy: Festschrift in Honor of Emerita S. Quito (Manila: De La Salle University, 1990), 78.

${ }^{3}$ Ibid., 79.

(c) 2016 Leslie Anne L. Liwanag

http://www.kritike.org/journal/issue 18/liwanag june2016.pdf

ISSN 1908-7330

(cc) BY-NC-ND 
(appetite), ang kagustuhan ng tao, at kung anong uri ng kagustuhan ang ninanais ng tao. Pinatunayang malaya ang pagpapasya ng tao at ito ang nagtatalaga ng limitasyon ng nasabing kalayaan. Nanindigan ang kanyang pag-aaral kung paano nananalaytay ang kalayaan gayong may Divine Motion at nagpahayag ng detalyadong rason kung bakit hindi mareresolba ng tao ang ganitong problema.

Dahil lubos ang pagtuon ng UST sa diskursong Eskolastisismo at Tomismo, para kay Quito hindi nito nagawa ang malawakang pagtugon sa mga pangangailangan at mga inaasahan ng mga mag-aaral at guro sa pilosopiya ng bansa. Naunsyami sa sitwasyong ito si Quito noong mabuksan ang isipan mula nang bumalik siya galing sa Belgium. Bunsod nito, niyanig niya ang mga haligi ng akademya sa kanyang lektyur tungkol sa pilosopiya ni St. Thomas Moore hinggil sa kapwa-Fribourger na si Herbert Marcuse, na nanguna sa ideya ng "Great Refusal." Aniya: "...it must take the risk of failure for in doing so it can consolidate its strength and expose the banalities of civil obedience to a reactionary regime."

Bukod dito, malaki ang ambag ng kaisipan ni Louis Lavelle kay Quito kaya umangkla siya sa diskurso nito. Napatutunayan ito ng kanyang doktoradong disertasyong may titulong "La notion de la Libertè participèe dans la philosophie de Louis Lavelle" na isinumite sa Universite' de Fribourg, Switzerland noong 1965. Eksistensyalistang Katoliko ang turing ng mga pantas kay Lavelle. Lunduyan ng kanyang pilosopiya ang pagkadakila ng tao bilang isang Bagay na presensiyang total (presence totale). Saanman nakapaloob ang tao, doon din nakapaloob ang kanyang kamalayan at katalinuhan. ${ }^{4}$ Para sa kanya, hindi kailanman maipaliliwanag at nararapat lamang tanggapin na malawak ang kalayaan ng tao-hindi nilikha ng sarili o binigay lamang ng Diyos. Datapwat masasabing lubos ang kalayaan ng tao at lubos ang pagkakaloob ng Diyos.

Buhat nito, isang mapangahas na Quito ang natunghayan nang naging sandigan niya ang Alemang pilosopo at politikal na teorista na si Herbert Marcuse noong panahon ng Batas Militar. Malaki ang naging impluwensiya ni Marcuse sa Estados Unidos noong huling bahagi ng 1960s at unang bugso ng 1970s. Sentro sa kaisipan ni Marcuse ang pananaw ukol sa ganap na kalayaan ng sangkatauhan (total human emancipation) at pagbubuo ng sibilisasyong malaya mula sa panunupil. Ayon sa introduksyon ni Marjorie Evasco sa mga artikulo ni Quito mula 1965 hanggang 1970 sa festschrift, isa sa mga panulat ni Quito na may titulong "Herbert Marcuse and Contemporary Society" ang nagsilbing tila isang pagpihit ng gatilyo upang pumutok ang mobilisasyong pinangunahan ng mga mag-aaral ng UST at

${ }^{4}$ Ibid., 201.

(C) 2016 Leslie Anne L. Liwanag

http://www.kritike.org/journal/issue 18/liwanag june2016.pdf

ISSN 1908-7330

(c) $)$ BY-NC-ND 
pagtayo laban sa tuluyang pagkalusaw ng kamay na bakal ng pambansang administrasyon.

Bandang huli, mababatid na nangamba si Quito sapagkat mapupunta sa alanganin ang kanyang kapakanan noong rehimeng Marcos gawa ng kanyang panulat at aktibistang pilosopiya. Kaya matutunghayan mula sa kanyang mga artikulo noong 1971 hanggang 1980 na mas naging tampulan ng kanyang diskurso ang usapin ng diwang Pilipino, kasaysayan ng pilosopiya, komparatibong pilosopiya, at ilan pang mga kahalintulad na paksa. Mas pinagtuunang-pansin ni Quito ang nasyonalismo sa karunungang Pilipino bilang naging motibasyon niya sa pagsisimula nito sa larangan ng agham - panlipunan (social sciences). Naging batayan niya ang pagsusulong na ito upang kalaunang makabuo ng kanyang kontribusyon sa Pilosopiyang Pilipino.

\section{Replektibong Pananaw sa Pilosopiya sa Pilipinas ni Quito}

Labis ang atensyon ng bansa sa ekonomikong pagbangon (economic recovery) hanggang sa kasalukuyan, kaya ipinagdiinan ni Quito na hindi nakapagtatakang 'di nabibigyan ng wastong kahalagahan ang pilosopiya sa Pilipinas. ${ }^{5}$

Inihain ni Quito ang pagkakaiba ng academic at formal philosophy, gayundin ang grassroot at folk philosophy. Gayong hindi kasalukuyang nananalaytay ang academic at formal philosophy sa bansa, dahil limitado ang karamihan sa mga bulto ng pilosopikal na gawain sa eksposisyon ng dayuhang pilosopikal na teorya, ipinagdiinan naman ni Quito na mayaman ang sisidlan ng grassroots philosophy o folk philosophy, na hindi pa nasusuri ng mga maka-Kanluraning akademiko. Tinawag ni Quito ang tinaguriang "loose philosophy" bilang "diwang Pilipino" (Filipino spirit), "Volksgeist" (Folk spirit) at "Weltanschauung" (worldview). Naniniwala siyang hindi lamang malalimang pag-unawa sa sariling pambansa at kultural na identidad ang pagkabatid natin sa ganitong nibel at pakiwari sa pilosopiya, datapwat magkakaroon din ng mga konsepto, wika, at mga sistema ng pagiisip na maaaring gamitin upang bumuo at mapayabong ang sarili sa makabuluhan at makapangyarihang diskurso.

Pinagtuunang-pansin ni Quito ang katanungan kung bakit may kakulangan tungo sa pag-unlad ang academic at formal philosophy sa Pilipinas. Itinanghal niya ang sampung dahilan na hinati sa 1) mga salik sa politikal at kultural na klima; 2) mga salik na may kinalaman sa institusyonal at estruktural na pagkukulang ng ating mga unibersidad at kolehiyo; at 3) mga

${ }^{5}$ Jimenez, et. al., Kaganapan ng Isang Dalubhasa sa Pilosopiya, 9.

(c) 2016 Leslie Anne L. Liwanag

http://www.kritike.org/journal/issue 18/liwanag june2016.pdf

ISSN 1908-7330

(cc) BY-NC-ND 
salik na may kinalaman sa propesyonal na kapasidad ng mga propesor sa pilosopiya.

Itinurong dahilan ni Quito ang politika at kultura sa Pilipinas na hindi bukas sa mabusising pamimilosopiya at pilosopikal na pananaliksik. Kung babalikan, dagdag niya na ang kasaysayan ng bansa sa ilalim ng kolonya ng Espanyol, Amerikano, at Hapon ang pumigil sa kalayaang mamilosopiya sapagkat hindi ito sang-ayon sa kanilang interes bilang mga pinunong kolonisador, at nangangambang baka kalaunang tugisin ng mga sinaunang Pilipino ang walang-patawad nilang pananakop sa lupang sinilangan.

Samakatuwid, noong isinulat ni Quito ang kanyang dalawang pangunahing obra noong 1970s at 1980s, mayroon lamang 30 hanggang 40 na taong tiyansa upang malayang umunlad mula sa banyagang kaisipan ang Pilosopiyang Pilipino. Ngunit kahit na natamo na ang politikal na "kalayaan" mula sa mga mananakop, hindi pa rin garantiya ang kalayaan sa kaisipan sapagkat nanatili ang mga Pilipino sa kolonyal na diskurso ng Eskolastisismo at Tomismo, at nagkaroon pa ng pagsesensor sa akademikong publikasyon mula 1970s hanggang sa unang bahagi ng 1980s. ${ }^{6}$

Sa kultural na aspekto, nabatid ni Quito na karaniwang nakaangkla ang konsepto ng pilosopiya sa maling konotasyon sa imahen ni Don Anastacio, kilala bilang "Pilosopo Tasyo" sa nobelang Noli Me Tangere ni Jose Rizal.7 Gayunman, sa halip na ipakahulugan ang pilosopiya sa matapang na panlipunang kritisismo ni Tasyo at pagsasawalang-bahala sa mga mapanlupig na kaugaliang kolonyal na lipunan, mas ikinakabit ang terminong pilosopiya sa pinagtatawanang imahen ng kabaliwan ng naturang karakter.

Sa mas espesipikong tagpuan ng mga unibersidad at kolehiyo sa Pilipinas, tinukoy ni Quito ang iba pang salik na nakapipinsala sa pag-unlad ng Pilosopiyang Pilipino. Kung ikukumpara sa pamantayan ng Europa, hindi nakauudyok ang mababang sweldo ng mga Pilipinong akademiko para magpursigi sa karera ang matatalinong mag-aaral na magturo sa kolehiyo at manaliksik. ${ }^{8}$ Para sa mga sumabak naman sa akademya, mababatid na nakagigipit ang karaniwang pagtatalaga ng dalawampu't apat na oras sa isang linggo para sa isang propesor sa kolehiyo para sa marubdob na pananaliksik at mas seryosong pamimilosopiya. ${ }^{9}$ Para sa masisipag at

${ }^{6}$ (Cf. Quito, "Teaching and Research of Philosophy in the Philippines" 713). Emerita Quito, "Teaching and Research of Philosophy in the Philippines," in A Life of Philosophy: Festschrift in Honor of Emerita S. Quito (Manila: De La Salle University, 1990), 713. This is the preliminary version of Quito's The State of Philosophy in the Philippines (1983). Cf. Emerita Quito, The State of Philosophy in the Philippines (Manila: De La Salle University Press, 1983).

${ }^{7}$ Quito, The State of Philosophy in the Philippines, 9. Translation mine.

${ }^{8}$ Quito, "Teaching and Research of Philosophy in the Philippines," 710.

${ }_{9}^{9}$ Ibid.

(C) 2016 Leslie Anne L. Liwanag

http://www.kritike.org/journal/issue 18/liwanag june2016.pdf

ISSN 1908-7330

(c) $)$ BY-NC-ND 
masisigasig sa pananaliksik at seryosong pamimilosopiya, gayong hindi maikakatwa ang kakapusan sa oras, mapagtatantong kinakapos sa imprastraktura para sa pag-aaral tulad ng grants, professorial chairs, at silidaklatan ang karamihan sa mga unibersidad at kolehiyo sa Pilipinas. ${ }^{10}$ Dagdag dito, hindi sapat ang paghikayat o pagbibigay ng insentibo sa mga guro at propesor ng mga unibersidad at kolehiyo sa Pilipinas para manaliksik at maglathala para sa publikasyon. ${ }^{11}$

Sa mas partikular pa na konteksto sa propesyonal na kapasidad ng mga Pilipinong guro at propesor sa Pilosopiya, tinukoy ni Quito ang iba pang nakakaperhuwisyong salik. May kakapusan sa gradwadong pagsasanay ang mga akademikong Pilipino gawa ng napakamahal na pag-aaral sa ibang bansa o maging sa sariling bayan. ${ }^{12}$ Para sa mga nais ipagpatuloy ang gradwadong programa sa sariling bansa, nasasadlak sila sa proseso ng inbreeding kung saan matutunan nila ang masaklap na akademikong kasanayang pagiging di-aktibo at di-produktubong propesor sa pananaliksik. ${ }^{13}$

Nalaman din ni Quito ang inkapasidad ng mga Pilipinong guro at propesor sa pilosopiya upang matutunan ang mga pangunahing lengguahe sa Europa bilang malaking hadlang sa pag-unlad ng Pilosopiyang Pilipino, dahil pipigilan nito ang direktang pag-unawa sa kaisipan ng mga nangungunang non-Anglophone European na pantas. ${ }^{14}$ Dagdag dito, isang kabalintunaan ang pirming paggamit ng Ingles imbis na sariling wika ng mismong mga Pilipinong guro at propesor sa pilosopiya. Ito ang pumipigil sa pag-unlad ng Pilosopiyang Pilipino sapagkat hindi ito sapat upang ipaunawa ang diwang Pilipino at malilimitahan ang komunikasyon sa pagitan ng mga mismong akademikong Pilipino at maging sa iba pang mga Pilipino. ${ }^{15}$

\section{Diskursibong Katayuan sa Pilosopiyang Pilipino ni Quito}

Sa pagpapamalas ng diskursibong katayuan sa Pilosopiyang Pilipino ni Quito, babalikan ang pag-aaral ni Demeterio na may titulong "Status of and Directions for "Filipino Philosophy" ni Zialcita, Timbreza, Quito, Abulad, Mabaquiao, Gripaldo, and Co na nagpapaliwanag sa taksonomiya at

\footnotetext{
${ }^{10}$ Ibid., 709.

${ }^{11}$ Ibid., 710.

12 Ibid., 711.

${ }^{13}$ Ibid., $710-711$.

${ }^{14}$ Ibid., 710.

${ }^{15}$ See number 10 of figure 3; Cf. Emerita Quito, "Ang Pilosopiya sa Diwang Pilipino," in A Life of Philosophy: Festschrift in Honor of Emerita S. Quito (Manila: De La Salle University, 1990),
} 200.

(c) 2016 Leslie Anne L. Liwanag http://www.kritike.org/journal/issue 18/liwanag june2016.pdf ISSN 1908-7330 


\section{PILOSOPIYA NI EMERITA QUITO}

peryodisasyon ng anyo ng Pilosopiyang Pilipino gawa ng replektibo at malalim na pananaliksik ukol dito.

Naging klaro para kay Demeterio na hindi posible ang pagsasagawa ng isa lamang ngunit komprehensibong eskemang magbibigay ng kabuoang taksonomiya at peryodisasyon ng bawat pantas, o maging ang pag-uugnay ng isang taksonomiya sa iba pa. Kaya sa pamamagitan ng pagsasantabi ng maliliit na kategorya (tinawag niyang "taxonomizer") at kronolohikal na tanda (tinawag na "periodizer"), at pagsasaayos ng mga anyo ng Pilosopiyang Pilipino, may pagkakataong maisakatuparan ang enggrandeng sintesis sa mukha ng isang dayagram upang mas makinita ang suma ng iba't iba ngunit magkakaugnay na kahulugan ng Pilosopiyang Pilipino.

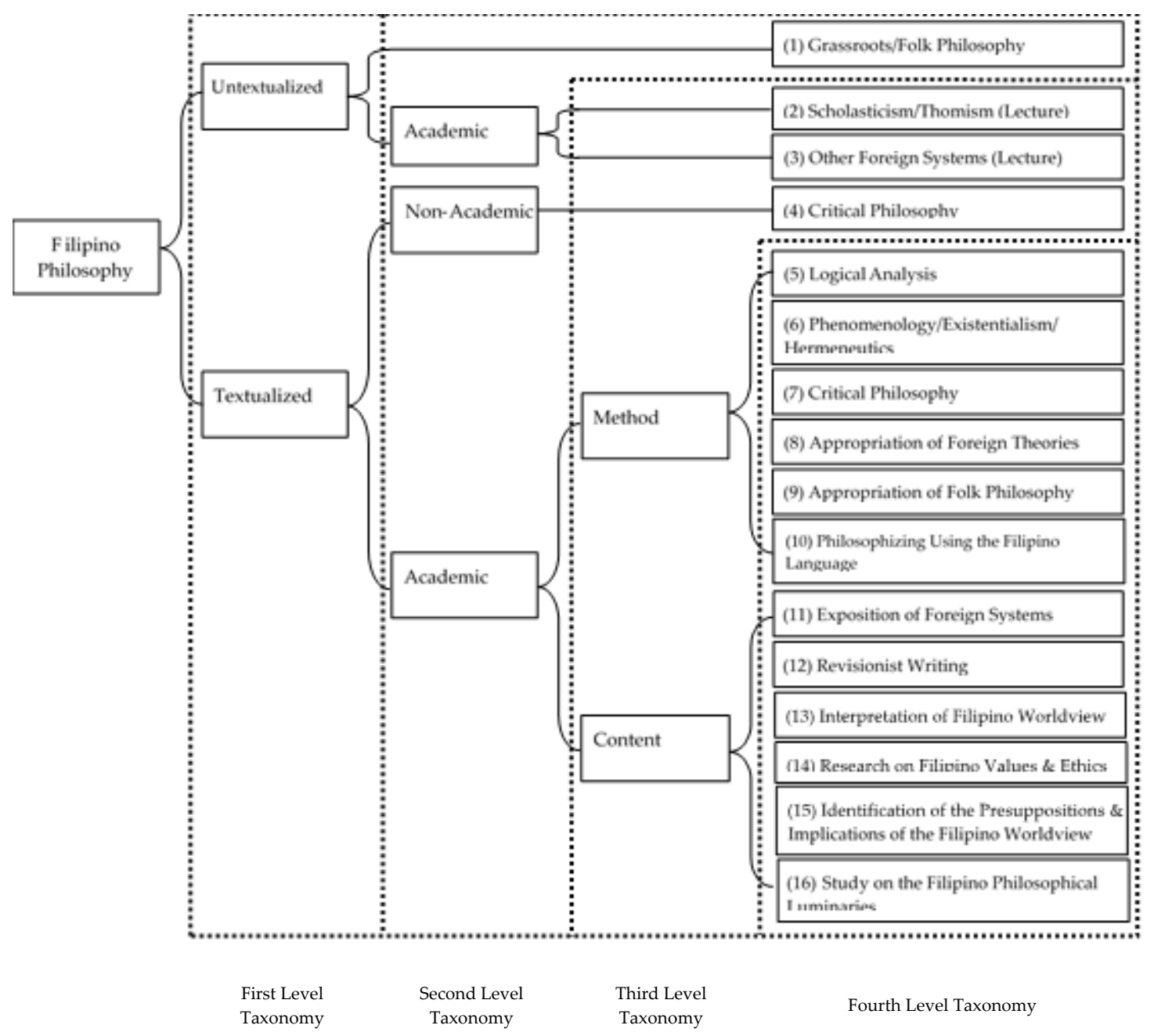

Figure 1: Ang Labing-Anim na Diskurso ng Pilosopiyang Pilipino ni Demeterio 
Bago ang lahat, minabuting isa-isahin ang paglalarawan ng mga taksonomiya kaakibat ng pagsusuri ng diskursibong katayuan para sa kaisipan ni Quito. Una, hindi nagmumula sa tekstwal na mga kaalaman ang kalikasan ng Grassroots or Folk Philosophy na nakabatay kina Quito at Gripaldo. Gayunman, magandang paksa ito sapagkat mauungkat ang identidad ng mga Pilipino bilang mga mamamayan ng bansa. Ikalawa, sinasakop ng Scholasticism and Thomism (lecture), na nakabatay kina Quito, Abulad, at $\mathrm{Co}$, ang mga pasimunong lektyur ng mga Pilipinong akademiko sa Eskolastisismo at Tomismo. Makabuluhan ito bilang panimulang pagsasanay sa pilosopiya, etika, at metapisika. Gayunman, nagiging hadlang ang dogmatismo at di-tekstwal na kalikasan nito para sa kaunlaran ng Pilosopiyang Pilipino.

Ikatlo, sinasaklaw ng Other Foreign Philosophical Systems (lecture), na nakabatay pa rin kina Quito, Abulad, at $\mathrm{Co}$, ang ilan sa mga punong-abalang mga Pilipinong akademikong naglelektyur ukol sa pilosopikal na sistema ng mga dayuhan. Kapaki-pakinabang ito sa pagkalusaw ng gahum ng Eskolastisismo. Gayunman, sagabal ang pagiging di-tekstwal na kalikasan nito sa kaunlaran ng pilosopiyang Pilipino. Ikaapat, ang Critical Philosophy as Non-academic Discourse, na nakabatay kina Zialcita, Quito, Mabaquiao, Timbreza, at Gripaldo, ay ukol sa praktika ng ilan sa mga intelektwal sa labas ng grupo ng mga Pilipinong akademiko sa pilosopiya. Makabuluhan at may kaugnayan sa konteksto ng Pilipinas na semi-pyudal, neo-kolonyal, at burukratikong-kapitalistang estado. May pakinabang ito lalo na't sentro nito ang kritikal na pilosopikal na balangkas.

Ikalima, kaugnay ng praktika ng Logical Analysis, na nakabatay kina Quito at Abulad, ang makapangyarihang metodo ng pamimilosopiyang nakaayon sa orihinal na tekstong Ingles. Nilalayon nitong maresolba ang pilosopikal na tunggalian sa pamamagitan ng pagbibigay-linaw sa wika at pagsusuri ng mga pahayag na karaniwang iginigiit. Isang pilosopikal na suliranin na may eksaktong lohikal na terminolohiya, mithiin nitong maresolba ang mga problemang sumusulpot gawa ng kalituhan sa lingguwistika. Maaaring magbukas ng iba pang pilosopikal na diskurso at panulat ang positibismong oryentasyon nito. Ikaanim, ang Phenomenology/Existentialism/Hermeneutics, na nakabatay pa rin kina Quito at Abulad, ay hinggil sa subhektibong interpretasyon, kairalan, kamalayan, kalayaan, pagpili ng tao upang magkaoon ng makapangyarihang pilosopikal na diskurso. Pero isang kahinaan nito ang pagkakabase sa Aleman at Pranses bilang mga paunang teksto ukol sa mga paksang ito.

Ikapito, ang Critical Philosophy, na nakabatay kina Zialcita, Timbreza, Quito, Mabaquiao, at Gripaldo, ay tungkol sa repleksyon at kritikal na pagsasapraktika ng ilang akademikong Pilipino sa larangan ng Pilosopiya. Praktikal ang gamit nito sa konteksto ng bansa sa pamamagitan ng pagsusuri

(c) 2016 Leslie Anne L. Liwanag

http://www.kritike.org/journal/issue 18/liwanag june2016.pdf

ISSN 1908-7330

(cc) BY-NC-ND 
ng kalagayan gamit ang pilosopiya, kaya lamang makikita sa kasaysayang naging sanhi ang Batas Militar sa Pilipinas upang mapayabong ang mga pananaliksik hinggil dito. ${ }^{16}$ Ikawalo, sumasangguni ang Appropriation of Foreign Philosophical Theories, na nakabatay kina Timbreza, Quito, Abulad, at Gripaldo, sa kapaki-pakinabang at may katuturang diskursong lumilikha ng intelektwal na dayalogo sa pilosopikal na teorya ng mga dayuhan at lokal na sitwasyon ng bansa, datapwat mapagtatantong kakaunting mga Pilipinong pantas ang sumusuong sa pilosopikal na diskursong ito. Nagagamit ito sa kontektwalisasyon at malikhaing aplikasyon sa sariling kultura at identidad ng mga nananahan sa partikular na tagpuan tulad ng Pilipinas.

Ikasiyam, pinag-uukulan ng Appropriation of Folk Philosophies, na nakabatay kina Timbreza, Quito, Mabaquiao, at Gripaldo, ang apropriyasyon ng katutubong pilosopiyang may layuning mapayaman ang lokal na mga konsepto at teorya. Alinsunod dito, sumusulpot ang isyung sapilitang paggamit ng pambansang wika sapagkat maraming Pilipinong pantas ang hindi sanay sa pagsusulat sa Filipino. Gayunman, kakikitaan pa ito ng bentahe gawa ng makabuluhang pagpapayabong ng konsepto at sistema ng kaisipang Pilipino. Ikasampu, may kinalaman sa naunang taksonomiya ang Philosophizing with the Use of the Filipino Language, na nakabatay kina Timbreza at Mabaquiao, sapagkat itinutulak pa rin ang kontekstwalisasyon gamit ang wika sa pamimilosopiyang nakaangkla sa karanasan ng Pilipinas. Sa kabilang banda, nakitang kahinaan lamang ang limitasyon ng tiyansang mailathala sa mga tanyag na abstraktong dyornal.

Ikalabing-isa, sinasakop ng Exposition of Foreign Philosophical Systems, na nakabatay kina Quito, Abulad, Co, at Gripaldo, ang mainam na panimulang punto ng tekstwal na kalikasan nito para sa apropriyasyon ng mga teoryang dayuhan. Isinisiwalat nito ang mga pilosopikal na kaisipang dayuhan upang kalaunang itulak sa pagsasakonteksto ng mga mababatid na mga sistema. Gayunman, may limitasyon pa rin ito para sa mga Pilipinong pantas sapagkat karamihan sa kanila, Ingles lamang ang nakakayang maunawaang wika. Ikalabing-dalawa, sinasaklaw ng Revisionist Writings, na nakabatay kay Gripaldo, ang mga pananaliksik na nagsasagawa ng kontribusyon sa pamamagitan ng paglampas sa kaisipan ng mga tanyag ng mga dayuhang pilosopo. Dahilan nito ang pagkakakilanlan at diskusyon ng internasyonal na komunidad. Subalit sa kasawiang-palad, iilang Pilipino lamang ang nakikipagsapalaran sa mga ganitong uri ng pilosopikal na pagaaral. Bukod dito, may akses lamang sila sa mga Ingles na panulat at hadlang pa ang eksklusibidad ng ilang archives ng mga espesipikong pilosopo. ${ }^{17}$

${ }^{16}$ Cf. F.P.A. Demeterio, “Status of and Directions for 'Filipino Philosophy' in Zialcita, Timbreza, Quito, Abulad, Mabaquiao, Gripaldo, and Co," in Philosophia: International Journal of Philosophy, 14:2 (2013), 209. Translation mine.

${ }^{17} \mathrm{Ibid} ., 210$.

(C) 2016 Leslie Anne L. Liwanag

http://www.kritike.org/journal/issue 18/liwanag june2016.pdf

ISSN 1908-7330

(c) BY-NC-ND 
Ikalabing-tatlo, umuukol ang the Interpretation of Filipino Worldview, na nakabatay kina Zialcita, Quito, Timbreza, Co, Abulad, Mabaquiao, at Gripaldo, sa pagpapalakas ng identidad ng mga Pilipinong pantas dahil sa publikasyon ng ilan sa kanila sa ganitong anyo ng pilosopikal na diskurso. Subalit karamihan mga Pilipino ang hindi nakauunawa sa katuturan at direksyon ng ganitong moda ng pamimilosopiya. Hindi pa rin naman katapusan ng mundo sapagkat ang mga obra at kontribusyon nina Zialcita at Quito ang gabay sa kaisipan at direksyon ng modang nito. Ikalabing-apat, kaugnay ng Research on Filipino Values and Ethics, na nakabatay kay Mabaquiao, ang pananaliksik sa halagahan at etika ng mga Pilipino. May kapakinabangan ito sa puntong nakahahalina ito sa gobyerno, relihiyon, at sibikong organisasyon. Iilan lamang ang sumasabak sa ganitong moda ng pamimilosopiya ngunit kung payayamanin at pagtutuunang-pansin, makikita ang pagkakaroon nito ng praktikal na dimensyon.

Ikalabing-lima, may katuturan ang Identification of the Presuppositions and Implications of Filipino Worldview, na nakabatay kina Zialcita at Gripaldo, sapagkat may makabuluhang gampanin at direksyon ang Pilosopiyang Pilipino bilang payak na interpretasyon ng pananaw sa mundo ng Pilipino (Filipino worldview). Gayong malabo ang mithiin ng pilosopiyang ito, mahalagang matapos na itanghal ang pananaw sa mundo ng Pilipino, kailangang ipamalas niya pa kung paano magagamit ang Pilosopiyang Pilipino sa kasalukuyan at sa hinaharap, kaya mas mabigat ang kanyang magiging responsibilidad. Ikalabing-anim, may kinalaman ang Study on the Filipino Pphilosophical Lluminaries, na nakabatay kina Timbreza at Gripaldo, sa pagpapasikat ng Pilipinong pilosopikal na korpus sa pamamagitan ng pagpaparaya sa mga Pilipinong magkaroon ng kanilang sariling tradisyon. Sa kabilang bada, marami sa mga Pilipinong iskolar ang kumukuwestiyon sa ingklusyon at ekslusyon ng ilang Pilipinong pantas sa listahan ng mga tunay na pilosopo..$^{18}$

Uumpisahan ang pagtuklas sa diskursibong katayuan ni Quito sa pilosopiyang Pilipino sa pamamagitan ng pag-uuri ng kanyang tekstwal na produksyon gamit ang iskema ng labing-anim na diskurso ng pilosopiyang Pilipino ni Demeterio. Ngunit bago pa man gawin ang pag-uuri sa mga obra ni Quito, maaari nang tanggalin ang unang apat na diskurso mula sa iskema ni Demeterio: 1) ang grassroots o folk philosophy, dahil malinaw na bilang isang propesor ng pilosopiya na walang kaugnayan ang diskursong ito sa mga obra ni Quito; 2) ang panayam tungkol sa Eskolastisismo at Tomismo, dahil pinaguusapan dito ang mga nailathala nang obra; 3 ) ang panayam tungkol sa iba't ibang banyagang sistemang pilosopiya, batay sa parehong kababanggit pa lamang na dahilan; at 4) kritikal na pilosopiya bilang hindi-akademikong

${ }^{18} \mathrm{Ibid} ., 211$.

(c) 2016 Leslie Anne L. Liwanag

http://www.kritike.org/journal/issue 18/liwanag june2016.pdf

ISSN 1908-7330

(cc) BY-NC-ND 
diskurso, dahil akademiko ang kabuoang konteksto ng pamimilosopiya ni Quito. Kaya sa halip na labing-anim na diskurso, labing dalawang diskurso na lamang ang gagamitin para sa pag-uuri sa mga obra ni Quito. Makikita sa Table 2 kung ano at ilan ang porsyento ng mga obra ni Quito ang kabilang sa nabanggit na labing-dalawang diskurso ng pilosopiyang Pilipino:

\begin{tabular}{|c|c|c|c|}
\hline Taksonomiya & Titulo & $\begin{array}{l}\text { Bilang ng } \\
\text { mga Akda }\end{array}$ & Percentage \\
\hline Logical Analysis & & 0 & $0.0 \%$ \\
\hline $\begin{array}{l}\text { Phenomenology / } \\
\text { Existentialism / } \\
\text { Hermeneutics }\end{array}$ & $\begin{array}{l}\text { "Existential Principles and Christian Morality," } \\
\text { "Reflections on the Death of God," at "An } \\
\text { Existential Approach to Ecumenism" }\end{array}$ & 3 & $9.1 \%$ \\
\hline Critical Philosophy & $\begin{array}{l}\text { "Should Communism Be Taught in Our } \\
\text { Universities," “The Role of the University in } \\
\text { Changing Women's Consciousness," “Ang } \\
\text { Kayamanan ng Wikang Filipino," "Ang Pilosopiya: } \\
\text { Batayan ng Pambansang Kultura," } \\
\text { "Teaching and Research of Philosophy in the } \\
\text { Philippines," at "Philosophy of Education for } \\
\text { Filipinos" }\end{array}$ & 6 & $18.2 \%$ \\
\hline $\begin{array}{l}\text { Appropriation of } \\
\text { Foreign Theories }\end{array}$ & $\begin{array}{l}\text { "Should Communism Be Taught in Our } \\
\text { Universities," at "Ang Pilosopiya sa Diwang } \\
\text { Pilipino" }\end{array}$ & 2 & $6.1 \%$ \\
\hline $\begin{array}{l}\text { Appropriation of } \\
\text { Folk Philosophy }\end{array}$ & & 0 & $0.0 \%$ \\
\hline $\begin{array}{l}\text { Philosophizing } \\
\text { using the Filipino } \\
\text { Language }\end{array}$ & $\begin{array}{l}\text { “Ang Pilosopiya sa Diwang Pilipino," “Kasaysayan } \\
\text { ng Pilosopiya," “Ang Kayamanan ng Wikang } \\
\text { Filipino," “Ang Pilosopiya: Batayan ng } \\
\text { Pambansang Kultura,” at “Isang Teoriya ng } \\
\text { Pagpapahalaga” }\end{array}$ & 5 & $15.2 \%$ \\
\hline $\begin{array}{l}\text { Exposition of } \\
\text { Foreign Systems }\end{array}$ & $\begin{array}{l}\text { "A New Concept of Philosophy," “La Notion de la } \\
\text { Liberte Participee dans la Philosophie de Louis } \\
\text { Lavelle," "Herbert Marcuse and Contemporary } \\
\text { Society," “The Philosophy of Henri Bergson," “The } \\
\text { Symposium of Plato," “The Phenomenology of } \\
\text { Edmund Husserl," “The Theme of Absurdity in } \\
\text { Albert Camus," “Ang Pilosopiya sa Diwang } \\
\text { Pilipino," “Ang Kasaysayan ng Pilosopiya," } \\
\text { "Oriental Roots of Occidental Philosophy," “Four } \\
\text { Essays in the History of Philosophy," “Lectures on } \\
\text { Comparative Philosophy," “Structuralism: A } \\
\text { General Introduction," "Robert Ardrey: Scientist } \\
\text { and Philosopher," “The Historical Concept of Being } \\
\text { and Truth," “The Philosophy of the Renaissance: } \\
\text { Nicolas of Cusa," “Yoga and Christian Spirituality," }\end{array}$ & 22 & $66.7 \%$ \\
\hline
\end{tabular}




\begin{tabular}{|c|c|c|c|}
\hline & $\begin{array}{l}\text { "Process Philosophy: An Introduction," "Homage } \\
\text { to Jean-Paul Sartre," “Three Women Philosophers," } \\
\text { "Values as a Factor in Social Action," at "Isang } \\
\text { Teoriya ng Pagpapahalaga" }\end{array}$ & & \\
\hline Revisionist Writing & & 0 & $0.0 \%$ \\
\hline $\begin{array}{l}\text { Interpretation of } \\
\text { Filipino Worldview }\end{array}$ & $\begin{array}{l}\text { "Lectures on Comparative Philosophy," “Ang } \\
\text { Pilosopiya: Batayan ng Pambansang Kultura," } \\
\text { "Teaching and Research of Philosophy in the } \\
\text { Philippines," " Structuralism and the Filipino } \\
\text { Volksgeist," at "Philosophy of Education for } \\
\text { Filipinos" }\end{array}$ & 5 & $15.2 \%$ \\
\hline $\begin{array}{l}\text { Research on Filipino } \\
\text { values and Ethics }\end{array}$ & $\begin{array}{l}\text { "Lectures on Comparative Philosophy," "Ang } \\
\text { Pilosopiya: Batayan ng Pambansang Kultura," } \\
\text { "Teaching and Research of Philosophy in the } \\
\text { Philippines," "Values as a Factor in Social Action," } \\
\text { "Structuralism and the Filipino Volksgeist," at } \\
\text { "Philosophy of Education for Filipinos" }\end{array}$ & 6 & $18.2 \%$ \\
\hline $\begin{array}{l}\text { Identification of the } \\
\text { Presuppositions \& } \\
\text { Implications of the } \\
\text { Filipino Worldview }\end{array}$ & & 0 & $0.0 \%$ \\
\hline $\begin{array}{l}\text { Study on the } \\
\text { Filipino } \\
\text { Philosophical } \\
\text { Luminaries }\end{array}$ & & 0 & $0.0 \%$ \\
\hline
\end{tabular}

Table 2: Mga Titulo, Bilang at Percentage ng mga Akda ni Quito sa Bawat Diskurso ng Pilosopiyang Pilipino ayon kay Demeterio

Ang nilalaman ng Table 2 ay biswal na ipinapakita ng radar chart sa Figure 2:

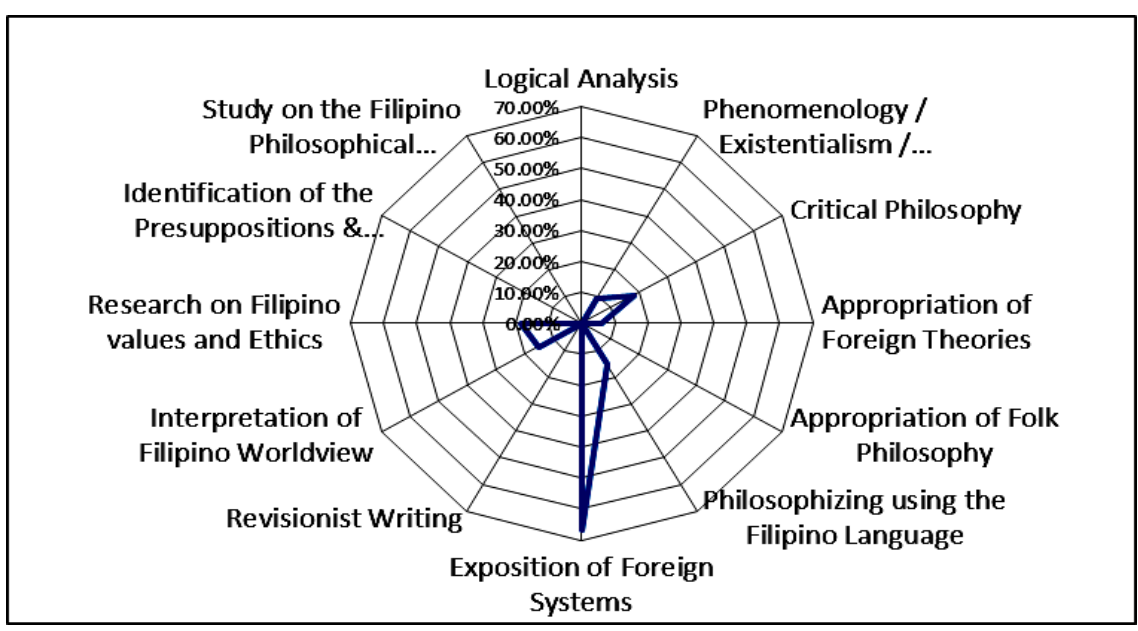

(C) 2016 Leslie Anne L. Liwanag http://www.kritike.org/journal/issue 18/liwanag june2016.pdf 
Figure 2: Radar Chart ng Porsyento ng mga Akda ni Quito sa

Bawat Diskurso ng Pilosopiyang Pilipino ayon kay Demeterio

Mula rito, makikita ang limang nangungunang diskurso ni Quitoang exposition of foreign systems (66.7\%); critical philosophy (18.2\%); research on Filipino values and ethics (18.2\%); philosophizing using the Filipino language (15.2\%); at interpretation of Filipino worldview (15.2\%). Samantalang walang nailathala si Quito na obra sa mga diskurso ng logical analysis, appropriation of folk philosophy, revisionist writing, identification of the presuppositions and implications of the Filipino worldview, at study on the Filipino philosophical luminaries.

\section{Metodo sa Pamimilosopiya ni Quito}

Para alamin ang metodo sa pamimilosopiya ni Quito, sisipatin ng papel na ito ang paraan na kanyang ginamit sa kanyang limang nangungunang diskurso sa pilosopiyang Pilipino na natuklasan sa naunang seksyon: ang exposition of foreign systems, critical philosophy, research on Filipino values and ethics, philosophizing using the Filipino language, at interpretation of Filipino worldview.

Hindi mga problem-based na akda ang mga obra ni Quito na napabibilang sa diskursong exposition of foreign systems, marahil sa dahilang dati na niyang mga panayam sa klase o sa mga okasyong inimbitahan siya ng anomang organisasyong magsalita tungkol sa pilosopiya. Sa konteksto ng kasalukuyang panahon, maaaring maliitin ng mga Pilipinong mananaliksik ang ganitong uri ng mga obra, ngunit mahalaga ang mga ito kapag isasakonteksto sila sa panahon kung kailan nilalabanan ng mga akademikong tulad ni Quito ang hegemonya ng Eskolastisismo at Tomismo. Archival at library research ang pangunahing metodo niya para sa mga akdang napabibilang sa diskursong ito. Pinakinabangan niya nang husto ang kanyang kaalaman sa iba't ibang banyagang wika para sa pagkalap ng kanyang mga teksto at ipinaliwanag niya ang mga banyagang sistema ng pilosopiya sa paraang madaling maintindihan ng kanyang mga mambabasang walang iba kundi ang mga Pilipinong mag-aaral at guro sa pilosopiya.

Mga problem-based na akda naman ang mga obra ni Quito na napabibilang sa diskursong critical philosophy. Bilang isang intelektuwal, batid niya ang mga suliranin, mga institusyonal at kultural na pagkukulang na bumabagabag sa lipunang Pilipino. Ginamit niya ang pilosopiya para mailahad ang mga suliranin at pagkukulang na ito, masuri ang mga sanhi, at madalumat ang mga hakbang na maaaring gawin para tugunan ang mga nasabing suliranin at pagkukulang. Marxismo, feminismo, nasyonalismo, at

(C) 2016 Leslie Anne L. Liwanag

http://www.kritike.org/journal/issue 18/liwanag june2016.pdf

ISSN 1908-7330

(cc) BY-NC-ND 
post-kolonyalismo ang malalawak na diskursong ginamit ni Quito bilang kontekstuwal na balangkas ng kanyang critical philosophy.

Mga problem-based rin na akda ang mga obra ni Quito na napabibilang sa diskursong research on Filipino values and ethics. Bilang isang propesor sa pilosopiya, etika, axiolohiya, at bilang intelektuwal, batid ni Quito ang malawak na puwang sa pagitan ng Kanluraning etika at axiolohiya sa isang banda at ng Pilipinong etika at axiolohiya sa kabilang banda. Ginamit niya ang pilosopiya para matalakay ang puwang na ito at mapag-usapan ang posibilidad ng pagtatag ng isang artikuladong Pilipinong etika at axiolohiya na silang tutugon sa mga pagkukulang ng mga Pilipino sa usapin ng panlipunang moralidad at katarungan. Ginamit ni Quito sa kanyang mga akdang napabibilang sa diskurso ng research on Filipino values and ethics ang mga metodo at kontekstuwal na balangkas na komparatibong pag-aaral, istrakturalismo, panlipunang kritisismo, at nasyonalismo.

Napabibilang rin sa una nang nabanggit na tatlong diskurso ang mga obra ni Quito na napabibilang sa diskursong philosophizing using the Filipino language, kaya iba't iba ang metodong pinagbabatayan ng mga obrang ito. Ngunit mahalagang banggitin na isang mahalagang metodo para kay Quito ang paggamit sa wikang Filipino sa pamimilosopiya-para maging mas makabuluhan ang pamimilosopiya sa mga Pilipino, para maging mas malapit ang pamimilosopiya sa diwang Pilipino, at para magkaroon ng mas malaking tiyansang tuluyang mabuo ang isang tunay na pilosopiyang Pilipino.

Mga problem-based ring akda ang mga obra ni Quito na napabibilang sa diskursong interpretation of the Filipino worldview. Bilang isang propesor sa pilosopiya, sinabayan ni Quito ang pinauso ni Leonardo Mercado na pagtatangkang bigyan ng sapat na pilosopikal na deskripsyon ang Pilipinong identidad na pinagkakaabalahan rin ng ilang kilusan sa larangan ng agham panlipunan tulad ng sikolohiyang Pilipino ni Virgilio Enriquez, pantayong pananaw ni Zeus Salazar, at Pilipinolohiya ni Prospero Covar. Ginamit ni Quito ang pilosopiya para matalakay ang saysay ng ganitong intelektuwal, pang-akademikong gawain, at makapag-ambag ng ilang preliminaryong pagbibigay deskripsyon sa Pilipinong identidad at pananaw sa mundo. Ginamit ni Quito sa kanyang mga akdang napabibilang sa diskurso ng interpretation of the Filipino worldview ang mga metodo at kontekstuwal na balangkas na komparatibong pag-aaral, istrakturalismo, panlipunang kritisismo, nasyonalismo, at post-kolonyalismo.

\section{Praksiyolohiya ni Quito}

Matapos maunsyami sa Tomismo ng UST at mabilad sa iba pang mga kaisipan sa Europa, tatlong pangunahing obra ni Quito sa anyong aklat at

(c) 2016 Leslie Anne L. Liwanag

http://www.kritike.org/journal/issue 18/liwanag june2016.pdf

ISSN 1908-7330

(cc) BY-NC-ND 
monograph ang nailathala mula taong 1967 hanggang 1970-A New Concept of Philosophy (1967), La Notion de la Liberte Participee dans la Philosophie de Louis Lavelle (1969), at Herbert Marcuse and Contemporary Society (1970). Maituturing na kontrobersyal ang huling nabanggit na panulat sa dahilang itinuturo itong nagtulak ng ilang protesta ng mga mag-aaral sa UST noong rehimeng Marcos.

Noong panahon ding iyon, naging bisitang propesor siya sa kursong Pilosopiya sa Pamantasang Ateneo De Manila, Kolehiyo ng De La Salle (Pamantasang De La Salle na ngayon), at Kolehiyo ng Asumsyon, kaya naging mas malawak ang kanyang impluwensiya sa mga mag-aaral na nasa kalagitnaan ng aktibong mobilisasyon.

Bilang pinuno ng Dibisyon ng Humanidades sa gradwadong programa noong 1970 sa UST, ginising niya ang kamalayan ng akademya kaakibat ang lekturang St. Thomas Moore kung saan kabilang si Marcuse, na nagpasingaw ng ideya ukol sa the Great Refusal. ${ }^{19}$ Mula rito, madadalumat ang pagiging radikal ni Quito sa nasabing unibersidad at nagsilbing inspirasyon sa kabataang aktibista noong panahong kinakaharap ng Pilipinas ang matinding panlipunang transpormasyon kung saan maliwanag na nanindigan siya sa kapangyarihan ng pagbalikwas. Sa yugtong ito pa nasaksihan ang agresibong bersyon ni Quito nang hamunin ang mga fakulti ng UST at iba pang pamantasang tila walang pakialam sa panlipunan at politikal na puwersang bumabalot sa bansa. ${ }^{20}$ Buhat dito, Abril ng taong iyon, isang tanong niya ang gumimbal sa mga pader ng akademya - "Maaari bang ituro ang komunismo sa mga unibersidad?" - na inilathala sa Horizon magasin ng Pamantasang De La Salle.

Noong 1978, ang imbitasyon sa Asian Women's Institute, India upang basahin ang kanyang papel na "The Role of the University in Changing Women's Consiousness" at ang pagtungo sa Ewha Woman's University, Korea ang naging dahilan kung bakit nagkaroon ng ugnayan si Quito sa pangkababaihang mga grupo at publikasyon ng monograph hinggil sa kababaihang pilosopo.

Alinsunod dito ang kanyang pagiging mas pamilyar sa matatalas na konseptwal na pamamamaraan ng Marxismo sa pamamagitan ng kanyang malalim na kaalaman sa kaisipan nina Marcuse at Sartre. Panahon ng Batas Militar nang mapailalim si Quito sa paghihikahos ng bansa mula sa paglabag ng karapatang-pantao. Bilang tagasunod ng kaisipan ni Marcuse, naniwala si Quito na kinakailangang siyasatin ang isyu ng karahasan sa lipunan. Kinakailangang wasakin ng indibidwal ang sistema upang makamit ang

\footnotetext{
${ }^{19}$ Marjorie Evasco, “Introduction to Part I: 1965-1970," in Emerita Quito, A Life of Philosophy: Festschrift in Honor of Emerita S. Quito (Manila: De La Salle University, 1990), 3.

${ }^{20} \mathrm{Ibid}$.

(c) 2016 Leslie Anne L. Liwanag

http://www.kritike.org/journal/issue 18/liwanag june2016.pdf

ISSN 1908-7330
}

(c) BY-NC-ND 
kalayaan. Kinakailangang lumabas siya mula sa Establisyamento liban na lamang kung gusto niya talaga ang karanasan ng alienasyon.

Maituturing na konsepto ni Georg Hegel (1770-1831) at Karl Marx (1818-1883) ang alienasyon. Dito nakapokus ang pilosopiya ni Marcuse na naging sandigan ng kaisipan ni Quito. Buhat nito, walang-kailang nananalaytay ang alienasyon sa larangan ng trabaho. Tinutukoy nito ang indibidwal na sinusubukang punan ang kanyang pangangailangan sa pamamagitan ng pagtatrabaho, pero ang totoo, makikitang nagiging kalakal (commodity) siya sa mismong prosesong nito. Hindi nakapagtatakang gawa ng pagsunod sa kaisipan ni Marx, sinabi ni Marcuse na isang anyo ng dehumanisasyon ang pag-unlad, "nagdudulot pa rin ng kasalatan at pagpapakasakit ang mataas na produktibong proseso ng pagtatrabaho, nagiging sanhi ang pagtaas ng antas ng kasaganaan ng kahirapan." 21

Gayunman, kasabay ng masaganang panahon ng dekada sisenta at mas lumalim pang praksiyolohiya ni Quito, mababanaag na naging maamong iskolar siya at umatras siya sa pagkanti ng usaping politika. Katunayan, ika-8 ng Pebrero, 2002 sa isang open forum ng symposium na may temang "Philosophy as Critique of Society and Institutions" sa UST, nagkaroon ng pambihirang pagkakataon si Demeterio upang tanungin si Quito kung ano ang nangyari sa Pilosopiyang Pilipino noong panahon ng Batas Militar. Hindi inaasahan ng mga kalahok ang kanyang kasagutan nang sabihing nakonsiyensya siya sa pangyayari. Paglalahad niya, dumating pa sa puntong isang ahente ng rehimeng Marcos ang sinadya siya upang alisin ang kritikal na bahagi ng isa sa kanyang ililimbag na aklat. Mula noon, hindi na siya muling nakipagsapalaran sa mapanuring kritisismo.

Bukod sa tumuon ito sa pagiging aktibo bilang Tagapangulo ng Departamento ng Pilosopiya sa Pamantasang De La Salle at nagsagawa ng apat na artikulo ukol sa Istrukturalismo, mas umikot na ang kanyang mga panulat sa mga temang may kinalaman sa oryentalismo at oksidentalismo, isipan, propagasyon ng Filipino sa akademya, diwang Pilipino, at ang Diyos. ${ }^{22}$

Nakaangkla ang pagsasapraktika niya bilang intelektwal sa paglalarawan ni Benda sapagkat akademiko si Quito, gayunman pinatahimik siya ng sistemang tinutuligsa sapagkat nasa ilalim siya ng pamumuno ng rehimeng Marcos. May pagtatangka si Quito na punan ang pagpapakahulugan ni Said sa mga intelektwal na kinakailangang may

${ }^{21}$ Emerita Quito, "Herbert Marcuse and Contemporary Society," in A Life of Philosophy: A Festschrift in Honor of Emerita S. Quito (Manila: De La Salle University, 1990), 120-121.

22 Estrellita Gruenberg, "Introduction to Part II: 1971-1980," in Emerita Quito, A Life of Philosophy: Festschrift in Honor of Emerita S. Quito (Manila: De La Salle University, 1990), 198.

(c) 2016 Leslie Anne L. Liwanag http://www.kritike.org/journal/issue 18/liwanag june2016.pdf ISSN 1908-7330 
pagsalungat (defiance) upang magkaroon ng sariling paninindigan at boses na nagpapamalas ng kalayaan at maibukod ang sarili mula sa nananaig na puwersa sa lipunan, pero kalaunang naging tikom siya sa aktibong politikal na pamimilosopiya. Hindi naman daw ito nakapagtataka ayon kay Timbreza sapagkat may pinoprotektahang pamilya at mas nanaisin na lamang ang kaligtasan ng bawat isa. ${ }^{23}$ Sa naging diskusyon ng intelektwal na talambuhay ni Quito, makikitang pumasok siya sa pagtingin ni Bourdieu sa intelektwal na batid dapat ang mga isyung kinakailangang pakialaman, nanahimik nga lamang gawa ng dehadong politikal na sitwasyon ng bansa. May angking kultural na kapital si Quito ayon kay Bourdieu gawa ng kanyang kaalamang propesyonal, katatasan sa pagsasalita, at matagal na pinaggugulang panahon sa pag-aaral at pananaliksik.

\section{Pananaw sa Lipunang Pilipino}

Mula sa malalimang pagbabasa ng kabuoang tekstwal na produksyon ni Quito sa festschrift, makikita sa mga sumusunod na pangunahing artikulo ang kanyang naging pagsusuri hinggil sa lipunang Pilipino na may pagkakasunod-sunod sa naturang aklat: 1) "Ang Pilosopiya sa Diwang Pilipino (1972)"; 2) "Lectures on Comparative Philosophy (1979)"; 3) "The Role of the University in Changing Women's Consciousness (1978)"; 4) "Ang Kayamanan ng Wikang Pilipino (1977)"; at 5) "Ang Pilosopiya: Batayan ng Pambansang Kultura (1980)." Matingkad na makikita mula sa limang panulat ang mga temang tumatalakay sa lipunang Pilipino tulad ng: a) kasarilinang diwa bilang identidad; b) Kristiyanismo bilang relihiyon; c) liberasyon ng kababaihan; at d) pananaw sa sariling wika.

\section{Kasarilinang Diwa bilang Identidad ng Pilipino}

Buhat ng mga inihaing diskurso at pagpapakahulugan sa Pilosopiyang Pilipino, sinabi ni Quito na maaari ding maging tungkol ito sa karaniwang pananaw, isang diwa, isang pagtingin na nangangahulugang natatangi sa mga Pilipino. Masasaksihan ito sa panitikan at sining, mga halagahan at kaugalian; sa isang salita-isang Weltanschauung. ${ }^{24}$ Mahalagang

${ }^{23}$ F.P.A. Demeterio, "Thought and Socio-Politics: An Account of the Late Twentieth Century Filipino Philosophy," in F.P.A. Demeterio's Philosophy and Cultural Theory Page (April 2002), <https://sites.google.com/site/feorillodemeterio/thoughtandsocio-politics $>, 1$ February $2011,12$.

${ }^{24}$ Emerita Quito, "Lectures on Comparative Philosophy," in A Life of Philosophy: Festschrift in Honor of Emerita S. Quito (Manila: De La Salle University, 1990), 514. Translation mine.

(C) 2016 Leslie Anne L. Liwanag

http://www.kritike.org/journal/issue 18/liwanag june2016.pdf

ISSN 1908-7330

$((c))$ BY-NC-ND 
makita ang kahalagahan ng pananaw (Weltanschauung) para maunawaan ang diwa (Geist) na importante sa pagbubuo ng Pilosopiyang Pilipino.

Sa pananaw ni Quito, kakikitaan ng matinding sensitivity at pride na may rason ang mga Pilipino. Ang nasyonalistikong katangiang ito ang dahilan kung bakit matiisin at mapagpasensiya ang mga mamamayan ng bansa. Matiisin na tipong hindi agarang nagtatangka ng hakbang para sa pagbabago dahil takot sa kabiguan. Mas pipiliin na lamang ng mga Pilipinong manahimik habang nagdudusa kaysa sa mabigong mabago ang sistema. Kaya hindi nakapagtatakang ilang daang taon muna ang nakalipas bago magrebolusyon ang mga sinaunang mamamayan ng bansa laban sa mga mapagsamantalang mananakop..$^{25}$

Marami pang mga manunulat ang nagsasabing may kakulangan sa identidad ang mga Pilipino, pero senyales din ito ng nasyonalistikong pride dahil sa labis na pag-aatubili para makabuo nito. Gayong batid ng mga Pilipinong kakaiba sila sa lahat, nabigo pa rin ito sa pagbubuo ng tiyak na identidad. Ngunit ani Quito, kahit na hindi lantaran, hindi pa rin masasabing walang identidad ang lipunang Pilipino. ${ }^{26}$ Dagdag niya, mayroon tayong identidad, pero hindi katulad ng mga Chinese, Japanese, Indian, Negro, o Aryan na makikita sa pisikal na identidad. Makikita ang pagkakakilanlan ng lipunang Pilipino sa kasarilinang diwa (o soul identity).

Sanhi ng sensitivity ng mga Pilipino ang pagiging personal sa lahat ng bagay. Kapag may diskusyon o debate, panalo ang indibidwal, hindi ang isyu. Kadalasang nauuwi pa sa pag-aaway ang mga ito. Tuwing eleksyon, mas tinitingnan kung sino ang tatakbo kaysa sa kung ano ang plataporma ng indibidwal.

Sa kabilang banda, may bentahe at kahanga-hanga rin ang pagiging personal ng mga Pilipino. ${ }^{27}$ Hindi maitatatwa ito sa konsepto ng bayanihan tuwing panahon ng kalamidad, kagipitan, o kahirapan sa buhay. May kakayahang magbigay kahit pa ang pinakamahirap na Pilipino at maibahagi ang sarili para sa kapwa. Dahilan ng sensitivity ng Pilipino kaya nagiging emosyonal siya at eksplisit. Masasaksihan ito sa mga pinta, musika, literatura, at kahit pa sa pagpapahayag ng pananampalataya. Hindi na kinakailangan ng lubusang kilos o eksplanasyon; madaling mababatid ang nais ipahayag ng bawat isa.

Sa kabilang banda, gawa ng pananakop ng iba't ibang bansa sa Pilipinas, nagkaroon ng katangiang flexibilidad ang mga Pilipino upang makibagay maging sa puntong naikikintal na ang bawat kultura at kaugalian ng dayuhan, habang nasasakripisyo at naisasaalang-alang ang sariling kultura at identidad. Hanggang ngayon, hirap pa rin ang bawat isa upang

${ }^{25}$ Ibid., 515 .

${ }^{26}$ Ibid., 516.

${ }^{27}$ Ibid., 517.

(c) 2016 Leslie Anne L. Liwanag http://www.kritike.org/journal/issue 18/liwanag june2016.pdf ISSN 1908-7330 
malaman kung ano nga ba ang identidad ng lipunang kinagisnan, dinakip, at pinatay ng kolonisasyon ang pagbubuo ng sariling pagkakakilanlan bilang Pilipino.

Gayunman, naninindigan si Quito na hindi pa rin tuwirang naiwaksi ang kaibuturan ng pagiging isang Pilipino. Isapraktika man ng Pilipino ang relihiyon ng dayuhan, o manamit man ng pandayuhan, nagsisilbi lamang ito upang palakasin pa ang kanyang flexibilidad at mabuting kalikasan. Kinailangan lamang ng Pilipinong matutunang pakinabangan ang naging sitwasyon sa kasaysayan kung saan wala silang magagawa. ${ }^{28}$

Tatlo ang pinagmanahan ng kulturang Pilipino: relihiyon ng mga Kastila, teknolohiya ng mga Amerikano, at diwa ng mga Asyatiko. ${ }^{29}$

Taglay ng Pilipino ang "utang na loob," "hiya," "amor propio," "pakikisama," "ningas kugon," "patigasan," dahil sa labis na pagmamahal sa sarili. Ayaw nating napapahiya, at dahil sa orgulyo, gumagawa tayo ng marahas upang maibangon lamang ang ating puri. Nagmamatigas tayo sapagkat malaki ang ating amor propio. Ayaw nating masabing naisahan tayo. Kung minsan tumitigil tayo sa paghahangad ng isang magandang ideya (ningas kugon) dahil sa baka tayo mapahiya. ${ }^{30}$

Walang kasarilinang Pilipino kung pisikal na katangian ang hahanapin sa kanya. Bagkus mayroong kasarilinang diwa (soul identity) ang Pilipino at hango ito sa pilosopiyang taglay ng bayang Pilipino.

\section{Ang Kristiyanismo bilang Relihiyon}

Bilang pilosopong intelektwal na nananahan sa ikalimang pinakamalaking Kristiyanong bansa sa buong mundo, hindi itinanggi ni Quito na mananatili ding Kristiyano ang diwa ng kanyang panulat. Gayunpaman, hindi niya tuwirang itinakwil ang mga isipang taliwas sa pagiisip Kristiyano. Makikita sa isa sa kanyang artikulong pinamagatang Pilosopiya sa Diwang Pilipino ang tahasang nagsusuri ng iba pang kaisipan upang malaman ang kagalingang loob nito. Naniniwala siya na may halaga ang bawat teorya, gayong masama sa unang tingin. Makikita lamang ang kabutihang nakapaloob sa mga ito kung magsusumigasig lamang sa pagaaral ng mga diskurso nito. ${ }^{31}$

Bukod sa hayagang paglalahad ni Quito ng kanyang pananampalataya, hindi niya isinawalang-bahala ang katotohanang kabilang siya sa lipunang napakalawak ng sakop ng Kristiyanismo bilang relihiyon.

\footnotetext{
${ }^{28} \mathrm{Ibid} ., 522$.

${ }^{29}$ Emerita Quito, "Ang Pilosopiya: Batayan ng Pambansang Kultura," in A Life of Philosophy: Festschrift in Honor of Emerita S. Quito (Manila: De La Salle University, 1990), 686.

${ }^{30}$ Ibid., 687.

${ }^{31}$ Quito, “Ang Pilosopiya sa Diwang Pilipino," 202.
}

(c) 2016 Leslie Anne L. Liwanag http://www.kritike.org/journal/issue 18/liwanag june2016.pdf ISSN 1908-7330 
Aniya, "sumasampalaya tayo sa isang Maykapal." Mula rito, makikita na ipinagpapalagay na niya na awtomatikong Pilipino-Kristiyano ang magiging mambabasa ng kanyang akdang nakasulat sa wikang pambansa.

Para sa kanya, hinango ng lipunang Pilipino sa pag-iisip Kristiyanong nagsasaad na mayroong Diyos na namamahala at nagpapasya sa daigdig ang pananampalataya sa isang Maykapal. Naniniwala ang mga ito sa isang Diyos Persona, isang Amang mahabagin, na sa kabila ng kasamaan, mapapatawad pa rin. Nabilad sa kulturang Kristiyano at sa pag-iisip Kristiyano ang mga Pilipino ${ }^{32}$ gawa ng matagal na pananakop ng mga Espanyol sa Pilipinas. Bukod dito, ibinahagi ni Quito na naniniwala ang lipunang Pilipino sa sinasabi ng pag-iisip Kristiyano na nilalang ng Diyos ang tao at muli siyang tutungo sa Diyos. Ito aniya ang dahilan kung bakit anoman ang gawin ng tao, hindi siya liligaya kung hindi sa piling lamang ng Diyos.

\section{Liberasyon ng Kababaihan}

Inamin ni Quito na napakahirap iwaksi at baguhin ang tradisyonal na paniniwalang nararapat lamang nasa isang tahanan ang espasyo ng babae at ang pangunahing tunguhin niya ang pagluluwal ng mga anak. Napakatibay ng naging paniniwalang itong nakabaon sa sistema ng pag-iisip at buhay sa lipunang Pilipino. Ang pinakamalala sa lahat ang implikasyon na kapag itinuloy-tuloy ng babae ang kanyang karera sa pampublikong espasyo, napakalaking kabawasan ito sa kanya bilang isang babae. ${ }^{33}$

Palagay niya, nakaangkla ito sa kasaysayan ng katutubong Pilipino kung saan kinagisnang ang lalaki ang makikipagsapalaran sa labas upang maghanap ng makakain, habang sa bahay mananahan ang babae upang alagaan ang kanyang mga anak. Gayong dumating sa puntong lumipat at permanente na ang pagtira nila sa bayan, nanatili pa rin ang babae sa pribadong espasyo para sa mga gawaing-bahay. Dahilan ito upang mapirmi siya at unti-unting mawalan ng puwang at importansiya sa publiko.

Masaklap ang naging tagpo sapagkat nauwi ito sa pagkakaroon ng isteryotipo sa kaisipan ukol sa kababaihan. Tinrato ng kalalakihan ang kanilang mga asawa na pawang mga tagasilbi lamang at tinitingnan ang kanyang pagkababae bilang isang kahinaan. Sa paglipas ng panahon, kasabay ng ganitong moda ng pag-iisip ang naging moda ng buhay na hindi na kinuwestiyon kailanman.

\footnotetext{
${ }^{32}$ Quito, "Ang Pilosopiya: Batayan ng Pambansang Kultura," 687.

${ }^{33}$ Emerita Quito, "The Role of the University in Changing Women's Consciousness," in A Life of Philosophy: Festschrift in Honor of Emerita S. Quito (Manila: De La Salle University, 1990), 588. Tranlsation mine.
}

(c) 2016 Leslie Anne L. Liwanag http://www.kritike.org/journal/issue 18/liwanag june2016.pdf ISSN 1908-7330 
Sa pagkakaroon ng mga teknolohikal na pag-unlad, napagaan ang mga gawaing-bahay ng kababaihan. Kahit paano, nagkaroon siya ng kalayaan sa mabigat na gawaing-bahay at nagka-oras sa pagsapi sa ilang grupo, mobilisasyon, mga parent-teacher organization, at maging ang pagkakaroon ng posisyon sa gobyerno at karera sa unibersidad.

Matapos ang Ikalawang Digmaang Pandaigdig, masasabing nagkaroon ng paghalili ang posisyon ng kababaihan. Hindi naging sapat ang kinikita ng kalalakihan upang matugunan ang pangangailangan ng pamilya dahil sa tumagilid na estado ng ekonomiya. Kaya naging uso ang mga nagtatrabahong nanay para makadagdag ng pantustos sa pang-araw-araw. ${ }^{34}$

Sa pagkakataon at maging hanggang sa panahong ito, pinahintulutan ang liberasyon ng kababaihan upang maiangat at maitawid ang estado ng pamilya, bukod pa rito ang kontribusyong naiaambag niya sa kanyang bansa. Sa pananaw ni Quito, malaki ang maitutulong ng mga unibersidad upang magkaroon ng kamalayan at pag-unawa ang kababaihan sa kanilang karapatan, tungkulin, at kakayahan.

\section{Pananaw sa Sariling Wika}

Itinuturing na isang hiwaga ang larangan ng pilosopiya sa Pilipinas sapagkat nahihirapang dalumatin ng karaniwang mamamayan ang katuturan nito. Bagamat napakaraming artikulong nauukol sa pilosopiya, hindi ito kayang sisirin ng mga Pilipino gawa ng suliranin sa wika. Para kay Quito, hindi mangmang ang mga Pilipino datapwat lubos at natatangi ang katutubong talino at likas na karunungan nito. Kung maitatawid lamang ang mga ideya sa wikang mauunawaan ng lahat, tiyak ang kanyang kadalubhasaan sa naturang larangan. ${ }^{35}$

Walang ibang wika ang makapagpapaliwanag sa kaibuturan ng nais ipahayag ng Pilipino kundi ang kanyang sariling wika. Itinuturong dahilan ni Quito ang katamaran at pag-aatubili ng tao kaya hindi lubusang nagagamit ang wikang pambansa. ${ }^{36}$ Kalikasan ng tao ang magmahal sa sarili wika, pero dito sa sariling bayan, tila taliwas ang nangyayari. Ibinahagi ni Quito na "marahil dito lamang sa Pilipinas nagaganap ang mapait na pagtatalo tungkol sa wikang pambansa." 37 Dumating pa raw sa puntong noong kapanahunan niya, mas ipinagtatanggol ng mga intelektwal ang wikang Ingles. Kung may pagkukusa, pagtulak, at pagsusumikap sana, hindi malayong mapalalawak ang paggamit at pagmamahal sa sariling wika.

\footnotetext{
${ }^{34}$ Ibid., 589.

${ }^{35}$ Quito, “Ang Pilosopiya sa Diwang Pilipino," 200.

${ }^{36}$ Ibid., 201.

37 Emerita Quito, "Ang Kayamanan ng Wikang Pilipino," in A Life of Philosophy: Festschrift in Honor of Emerita S. Quito (Manila: De La Salle University, 1990), 600.
}

(C) 2016 Leslie Anne L. Liwanag http://www.kritike.org/journal/issue 18/liwanag june2016.pdf ISSN 1908-7330 
Karaniwan sa mga kabataan ay hindi naiintindihang mabuti ang mga wikang banyaga. Nakababasa man sila ng Ingles o Kastila, sila ay salat sa kakayahang magsalita at humubog ng katuturan. Naroon sa mga diwa ang ideya ngunit hindi mabigkas. Ang nakararaming Pilipino ay marunong magIngles, ngunit anong uri ng Ingles? Ano ang nasasabi at nasusulat ng karaniwang Pilipino? Ipinagmamalaki natin na ang ating bansa ay "Englishspeaking," ngunit kadalasan ay baluktot at halos hindi maintindihan ang ating pagbigkas. Ang Ingles ay hindi angkop sa ating diwa. ${ }^{38}$

Hindi layunin ni Quito na iwaksi sa kamalayan ang wikang Ingles. Huwag lamang sanang dumating ang araw na dahil sa lubos na pagka-maybukas-pinto ng Pilipino sa ibang wika tulad ng Ingles, maibabaon na sa limot ang sariling wika. Hindi sukatan ng kagalingan sa Ingles ang talino ng isang tao. Hindi rin maitatanggi ang angking katalinuhan ng Pilipino. Katibayan ang pagiging primera klase ng mga Pilipino kung talino ang pag-uusapan. Pruweba ang mga naging tanyag na kababayan sa kanilang natatanging imbensyon. Iminumungkahi ni Quito na bukod sa katotohanang ito, magagawa pa rin ng bawat dalubhasang makapagsulat at makapaglimbag ng mga sulatin gamit ang inang-wika na makatutulong 'di lamang sa kanilang disiplina, bagkus para sa kontribusyon ng karunungan maging sa mga karaniwang Pilipino.

\section{KONGKLUSYON}

Umiinog ang pilosopikal na diskurso ni Quito sa pagsusuri ng mga suliraning institusyonal, kultural, at politikal na kinakaharap ng larangan ng pilosopiya sa Pilipinas. Sentro sa kanyang diskurso ang pagsisiwalat ng mga dayuhang sistemang produkto ng kanyang kabihasaan sa iba't ibang wika. Gayunman, hindi pa rin nakalimot si Quito na maging katalista ng pamimilosopiya gamit ang wikang Filipino. Naninindigan siyang ito lamang ang makabubungkal ng kaibuturan ng nais ihayag at madaling mauunawaan ng mga kapwa-Pilipinong wala pang kasanayan sa anomang antas ng pamimilosopiya, kaya pinapatingkad na nararapat ang paglalathala ng mga pag-aaral sa wikang pambansa. Sa pagpokus niya sa teoretikal na pamimilosopiya sa akademya, winika niyang kailangang palusugin ang pagsusuri sa diwang Pilipino sapagkat ito ang natatanging identidad na maipagmamalaki ng bawat mamamayan sa buong mundo.

Para kay Quito, pinakapuso at susi ang wikang pambansa upang mabatid ang katuturan ng pilosopiya. Buhat nito, hinihikayat ni Quito ang paggamit ng inang-wika sa mga pag-aaral upang maipaabot ang kabuluhan maging sa mga karaniwang Pilipino.

${ }^{38}$ Quito, “Ang Pilosopiya: Batayan ng Pambansang Kultura," 688.

(c) 2016 Leslie Anne L. Liwanag

http://www.kritike.org/journal/issue 18/liwanag june2016.pdf

ISSN 1908-7330

(cc) BY-NC-ND 
Hayagan din ang kanyang pagkadismaya sa pagkakaroon ng “Women's Liberation Movement." Aniya, lalong ipinapakita ng mga samahang ito ang pagkaalipin ng kababaihan. Hindi nananaig ang diskriminasyon sa kanilang kasarian. Kapag angkin ng mga babae ang pagiging kwalipikado, nakukuha nila agad ang trabaho. Sa kabilang panig, ipinaliwanag ni Quito na saksi ang Kristiyanong bibliya sa pagiging pantay at likas na magkasangga ng dalawa. Mula sa tadyang ng lalaki ang babae upang maipakita na walang nakatataas sa isa. Gayundin, ang kwento nina Malakas at Maganda na sabay lumabas mula sa tinukang kawayan ng ibon. Paglilinaw ni Quito, ayon sa tala ng kasaysayan, mababanaag ang pagkakapantay ng mga lalaki at babae. Pareho ang pagkalinga sa sanggol na babae at lalaki; sila ang bahala pumili sa kanilang magiging esposo o esposa; pantay ang hatian sa mga mana at karapatan. Gayong nasa ilalim ng pamumuno ng mga Espanyol, kakikitaan din ng katapangan sina Gabriela Silang, Melchora Aquino, at Gregoria De Jesus.

Madaling-madali sa kanya ang diskursong exposition of foreign systems dahil nakuha niyang suriin ang iba pang preliminaryong pagsusuri gawa ng kabihasaan sa iba't ibang wika. Tinitingala si Quito sa malalim na teoretikal na pagsusuri kaya nakilala sa larangan ng pilosopiya. Dagdag dito, maliwanag ang kontribusyon sa diskusyon sa identidad na pinalitaw ni Quito kahit hindi pisikal na madedetermina sa mga Pilipino. Ipinagdiinan niyang nananalaytay sa bawat isa ang diwang Pilipinong maipagmamalaki sa buong mundo.

Hinggil sa usaping ito, madadalumat ang mga implikasyon ng mga saysay na ito sa pilosopiyang Pilipino. Una, titingkad ang kani-kaniyang pinahahalagahang prinsipyo sa oras na lumublob sa hinaharap na politikal na estado ng lipunan. Ikalawa, walang ibang moda ng komunikasyon ang makasisisid sa kaibuturan ng pilosopiya ng bayan kundi ang wikang pambansa. Ikatlo, isang bentahe ang kabatiran sa samu't saring wika upang mahukay ang iba pang preliminaryong kaisipang dayuhan.

Ikaapat, may kaugnayan ang naunang implikasyon sapagkat magiging matagumpay lamang ang paghuhukay ng ibang diskurso kung nasagot ang tawag ng kontektwalisasyon. "Ginagamit ang panghihiram sa mga paradaym at metodolohiya. Malayang nakahiram si Thomas Aquinas mula sa Arabiko, at malaki ang naging kontribusyon sa pilosopiyang Italyano. Humiram si Martin Heidegger mula kay Soren Kierkegaard, gaya ng ginawa ni Hans-Georg Gadamer sa kanyang panghihiram mula sa mga Griyego, pareho silang lubos ang naging ambag sa pagyabong ng ika-20 na siglo ng pilosopiyang Aleman. Samakatuwid, walang rason upang maging malaya ang pilosopiyang Pilipino mula sa panghihiram mula sa Kanluraning

(C) 2016 Leslie Anne L. Liwanag

http://www.kritike.org/journal/issue 18/liwanag june2016.pdf

ISSN 1908-7330

(cc) BY-NC-ND 
kaisipan." ${ }^{39}$ At ikalima, kinakailangan ang pagka-may-bukas-pinto sa ibang kultura, tradisyon, at maging sa pilosopiyang taliwas sa sariling paniniwala upang makita ang kagandahang-loob nito.

Madadalumat mula sa pag-aaral na ito ang pagiging dakilang Pilipinong pilosopo ni Quito. Hindi siya nakuntento sa lokal at tradisyonal na mukha ng pamimilosopiya. Bagkus lumabas siya ng Pilipinas upang pagtuunan ang debosyon sa pagtamo ng malalimang kaalaman. Noong matapos ito, bumalik si Quito sa bansa upang ibahagi ang produkto ng kanyang puspusang pag-aaral sa larangan ng pilosopiya.

Gayong nananahan sa krusyal na estado si Quito, tinapos niya ang pangangapa sa mga sinaunang pilosopo at nagbigay ng sapat na direksyon para sa mga pantas sa hinaharap. Nakahahanga ang minsang naging impluwensiya ni Quito sa kabataan upang mag-aklas laban sa mga anomalya ng gobyerno, sa pamamagitan ng kanyang eksposisyon sa kaisipang Marcuse. Naging instrumento si Quito upang maging malawak ang kaalaman sa iba't ibang mukha ng pilosopiya. Gayunman, ipinagdiinan niyang iwasan ang pagkakaroon ng mababang pagtingin at pagtatatwa sa sariling kultura, tradisyon, pilosopiya, o pananampalataya.

Mapagtatantong may limitasyon pa rin ang marangal at malaking kontribusyon ni Quito sa pamimilosopiya sa Pilipinas. Kapag susuriing mabuti ang radar chart ng bawat diskurso ng Pilosopiyang Pilipino, may kahinaan si Quito at walang nailimbag na obra sa mga diskurso ng logical analysis, appropriation of folk philosophy, revisionist writing, identification of the presuppositions and implications of the Filipino worldview, at study on the Filipino philosophical luminaries. Buhat ng pagkakatali sa mga hindi problem-based na diskurso ukol sa exposition of foreign systems, ginamit na lamang niya ang mga panayam sa klase o mga materyal sa mga imbitasyon sa pagsasalita ukol sa pilosopiya.

May kahinaan si Quito mula sa nabanggit na kalakasan nang gamitin ang kaisipan ni Marcuse noong panahon ng Batas Militar. Dumating ang puntong unti-unti nang dumadami ang bilang ng mga nakikibakang magaaral laban sa pamumuno ni Marcos. Naging sanhi ito upang mabahagbuntot siya sa aktibong politikal na pagdidiskurso at pinili ang sariling kaligtasan sa pagtuon sa mas ligtas na pamimilosopiya. Ayon sa mismong personal na kuwento, nakapanayam ni Demeterio si Quito ukol dito at inaming nagsisi sa kanyang naging hakbang. Makikita ring mula sa mga problemang ihinain na kinapos siyang magkaroon ng aktibong praksiyolohiya. Naging natatanging kaakibat ni Quito ang pagkakatali sa

39 F.P.A. Demetreio, “Rereading Emerita Quito's Thoughts Concerning the Underdevelopment of Filipino Philosophy," in F.P.A. Demeterio's Philosophy and Cultural Theory Page (October 1998), < https://sites.google.com/site/feorillodemeterio/re-readingemeritaquito $>, 1$ Februay 2011, 17.

(c) 2016 Leslie Anne L. Liwanag http://www.kritike.org/journal/issue 18/liwanag june2016.pdf ISSN 1908-7330 
teoretikal na pagsusuri gamit ang kanyang mga pag-aaral at panulat. Sa kontemporanyong panahon, maaari nating suungin o punan ang mga nailahad na pagkukulang na ito bilang mga iskolar ng pilosopiya sa bansa.

Datapwat makikita ang kanyang iilang mga pagkukulang, mailalagom na mahalaga pa rin ang naging papel ni Quito sa paglalangkap at kontektwalisasyon ng mga pilosopikal na kaisipan sa larangan ng edukasyon tungo sa kasaganahan ng tektwal na proyekto ng mga susunod pang henerasyon ng kabataan at mananaliksik.

Department of Filipino, De La Salle University, Philippines

\section{References}

Abulad, Romualdo, "Introduction," in Emerita Quito, A Life of Philosophy: Festschrift in Honor of Emerita S. Quito (Manila: De La Salle University, 1990).

Demeterio, F.P.A. and Leslie Anne Liwanag, "Ang Pilosopiya ni Pierre Bourdieu bilang Batayang Teoretikal sa Araling Pilipino," Kritike: An Online Journal of Philosophy, 8:2 (2014).

Demeterio, F.P.A., Assessing the Developmental Potentials of Some Twelve Discourses of Filipino Philosophy," in Philippiniana Sacra, 69:147 (May-August 2014).

"Rereading Emerita Quito's Thoughts Concerning the Underdevelopment of Filipino Philosophy," in F.P.A. Demeterio's Philosophy and Cultural Theory Page (October 1998), $<$ https://sites.google.com/site/feorillodemeterio/rereadingemeritaquito $>, 1$ February 2011.

"Status and Directions for 'Filipino Philosophy' in Zialcita, Timbreza, Quito, Abulad, Mabaquiao, Gripaldo, and Co," in Philosophia: International Journal of Philosophy, 14:2 (2013).

"Thought and Socio-Politics: An Account of the Late Twentieth

Century Filipino Philosophy," in F.P.A. Demeterio's Philosophy and Cultural Theory Page (April 2002), $<\underline{\text { https://sites.google.com/site/feorillodemeterio/thoughtandsocio- }}$ politics $>, 1$ February 2011.

Evasco, Marjorie, “Introduction to Part I: 1965-1970," in Emerita Quito, A Life of Philosophy: Festschrift in Honor of Emerita S. Quito (Manila: De La Salle University, 1990).

"Introduction to Part III: 1981-1988," in Emerita Quito, A Life of Philosophy: Festschrift in Honor of Emerita S. Quito (Manila: De La Salle University, 1990).

(C) 2016 Leslie Anne L. Liwanag

http://www.kritike.org/journal/issue 18/liwanag june2016.pdf

ISSN 1908-7330

(c) BY-NC-ND 
Gruenberg, Estrellita, "Introduction to Part II: 1971-1980," in Emerita Quito, A Life of Philosophy: Festschrift in Honor of Emerita S. Quito (Manila: De La Salle University, 1990).

Jimenez, Janet, et. al., Ang Kaganapan ng Isang Dalubhasa sa Pilosopiya (Thesis, Manila: De La Salle University, 1990).

Mahaguay, Jerwin, “Ang Pilosopiya ng Edukasyon para sa mga Pilipino ayon kay Emerita S. Quito," (Thesis, Manila: De La Salle University, 2013).

Quito, Emerita S., ed., "Pilosopiyang Pilipino," in Ensayklopidya ng Pilosopiya (Manila: De La Salle University Press, 1993).

Quito, Emerita S., "A Filipino Volkgeist in Vernacular Literature," in A Life of Philosophy: Festschrift in Honor of Emerita S. Quito (Manila: De La Salle University, 1990).

"Ang Kayamanan ng Wikang Pilipino," in A Life of Philosophy: Festschrift in Honor of Emerita S. Quito (Manila: De La Salle University, 1990).

"Ang Pilosopiya: Batayan ng Pambansang Kultura," in A Life of Philosophy: Festschrift in Honor of Emerita S. Quito (Manila: De La Salle University, 1990).

"Ang Pilosopiya sa Diwang Pilipino," in A Life of Philosophy: Festschrift in Honor of Emerita S. Quito (Manila: De La Salle University, 1990).

"Existential Principles and Christian Morality," in A Life of Philosophy: Festschrift in Honor of Emerita S. Quito (Manila: De La Salle University, 1990).

"Herbert Marcuse and Contemporary Society," in A Life of Philosophy: Festschrift in Honor of Emerita S. Quito (Manila: De La Salle University, 1990).

"Kasaysayan ng Pilosopiya," in A Life of Philosophy: Festschrift in Honor of Emerita S. Quito (Manila: De La Salle University, 1990).

"Lectures on Comparative Philosophy," in A Life of Philosophy: Festschrift in Honor of Emerita S. Quito (Manila: De La Salle University, 1990).

"Philosophy of Education for Filipinos," in A Life of Philosophy: Festschrift in Honor of Emerita S. Quito (Manila: De La Salle University, 1990).

"Should Communism Be Taught in our Universities," in A Life of Philosophy: Festschrift in Honor of Emerita S. Quito (Manila: De La Salle University, 1990).

"Structuralism and the Filipino Volkgeist," in A Life of Philosophy: Festschrift in Honor of Emerita S. Quito (Manila: De La Salle University, 1990).

(c) 2016 Leslie Anne L. Liwanag

http://www.kritike.org/journal/issue 18/liwanag june2016.pdf

ISSN 1908-7330 


\section{PILOSOPIYA NI EMERITA QUITO}

"Teaching and Research of Philosophy in the Philippines," in $A$ Life of Philosophy: Festschrift in Honor of Emerita S. Quito (Manila: De La Salle University, 1990).

"The Role of the University in Changing Women's Consciousness," in A Life of Philosophy: Festschrift in Honor of Emerita S. Quito (Manila: De La Salle University, 1990).

The State of Philosophy in the Philippines (Manila: De La Salle University Press, 1983). 